\title{
Article \\ Optimization of 2-Phenylethanol Production from Sweet Whey Fermentation Using Kluyveromyces marxianus
}

\author{
Monserrat Alonso-Vargas ${ }^{1}$, Alejandro Téllez-Jurado ${ }^{1}$, Carlos A. Gómez-Aldapa ${ }^{2, *} \mathbb{0}$, \\ María del Rocío Ramírez-Vargas ${ }^{1}$, Laura Conde-Báez ${ }^{1} \mathbb{D}$, Javier Castro-Rosas ${ }^{2} \mathbb{C}$ and Arturo Cadena-Ramírez ${ }^{1, *}$ \\ 1 Posgrado en Biotecnología, Universidad Politécnica de Pachuca, Carretera Pachuca-Cd. Sahagún, km 20, \\ Ex-Hacienda de Santa Bárbara, C.P. Zempoala 43830, Hidalgo, Mexico; \\ monsealonso@micorreo.upp.edu.mx (M.A.-V.); alito@upp.edu.mx (A.T.-J.); \\ rocioramirez@upp.edu.mx (M.d.R.R.-V.); laura_conde@upp.edu.mx (L.C.-B.) \\ 2 Área Académica de Química, Instituto de Ciencias Básicas e Ingeniería, Ciudad del Conocimiento, Carretera \\ Pachuca-Tulancingo, km 4.5, Col. Carboneras, Mineral de la Reforma, \\ C.P. Mineral de la Reforma 42184, Hidalgo, Mexico; jcastro@uaeh.edu.mx \\ * Correspondence: cgomeza@uaeh.edu.mx (C.A.G.-A.); arturocadena@upp.edu.mx (A.C.-R.)
}

Citation: Alonso-Vargas, M.; Téllez-Jurado, A.; Gómez-Aldapa, C.A.; Ramírez-Vargas, M.d.R.; Conde-Báez, L.; Castro-Rosas, J.; Cadena-Ramírez, A. Optimization of 2-Phenylethanol Production from Sweet Whey Fermentation Using Kluyveromyces marxianus.

Fermentation 2022, 8, 39. https://

doi.org/10.3390/fermentation8020039

Academic Editors:

Francesca Raganati and

Alessandra Procentese

Received: 19 December 2021

Accepted: 13 January 2022

Published: 19 January 2022

Publisher's Note: MDPI stays neutral with regard to jurisdictional claims in published maps and institutional affiliations.

Copyright: (c) 2022 by the authors. Licensee MDPI, Basel, Switzerland. This article is an open access article distributed under the terms and conditions of the Creative Commons Attribution (CC BY) license (https:// creativecommons.org/licenses/by/ $4.0 /)$.

\begin{abstract}
The growing demand for natural products benefits the development of bioprocesses to obtain value-added compounds using residues such as sweet whey, which is rich in lactose. The yeast Kluyveromyces marxianus can ferment sweet whey to obtain 2-phenylethanol (2-PhEtOH), which is a superior alcohol with a rose aroma. Such fermentation only requires the addition of L-phenylalanine (precursor) and $\left(\mathrm{NH}_{4}\right)_{2} \mathrm{SO}_{4}$ (salt). Therefore, it was sought to improve the fermentation conditions to produce 2-PhEtOH, which, in turn, would achieve the maximum decrease in the Chemical Oxygen Demand (COD) of the fermentation medium. With the use of the Response Surface Methodology and the application of a Central Composite Design for optimization, two parameters were evaluated as a function of time: salt concentration and precursor. The experimental data were adjusted to a second order polynomial, identifying that the precursor concentration presents a statistically significant effect. The best conditions were: $4.50 \mathrm{~g} / \mathrm{L}$ of precursor and $0.76 \mathrm{~g} / \mathrm{L}$ of salt, with a maximum production of $1.2 \mathrm{~g} / \mathrm{L}(2-\mathrm{PhEtOH})$ at $48 \mathrm{~h}$ and achieving a maximum percentage of COD removal of $76 \%$ at $96 \mathrm{~h}$. Finally, the optimal conditions were experimentally validated, recommending the use of the model.
\end{abstract}

Keywords: optimization; 2-phenylethanol; sweet whey; COD removal; Kluyveromyces marxianus

\section{Introduction}

The biotechnological production of aromatic compounds with pharmacological, food and cosmetic interest, has acquired greater importance. Since the production by chemical synthesis (Friedel-Crafts and Gringnard) and plant extraction, generates corrosive and toxic waste for humans and the environment [1-4] and makes difficult the use of aroma in the food industry where aroma legally labeled "natural" are required [5]. 2-Phenylethanol (2-PhEtOH) is a higher alcohol with a pleasant rosy aroma, whose demand increases between 10 and $15 \%$ each year and when it comes from natural sources, its market value may be higher than USD 1000 dollars $/ \mathrm{kg}$ [6]. It is important to note that its production is limited due to adverse effects linked to chemical synthesis, which makes it attractive to obtain by fermentation [7].

The production of 2-PhEtOH by fermentation has been well studied, obtaining in optimized processes up to $5.6 \mathrm{~g} / \mathrm{L}$ using well-defined and expensive culture media [2]. However, there is another variant of the fermentative methods for obtaining 2-PhEtOH, in which the use of agro-industrial residues as nutrients source for culture media has been explored, although there are few studies. When beet molasses was used as carbon sources supplemented with $7 \mathrm{~g} / \mathrm{L}$ of L-phenylalanine, $0.89 \mathrm{~g} / \mathrm{L}$ of 2-PhEtOH was achieved using Kluyveromyces marxianus [8]. With grape juice as the carbon source supplied with 5 
$\mathrm{g} / \mathrm{L}$ of L-phenylalanine, $0.77 \mathrm{~g} / \mathrm{L}$ of 2-PhEtOH was obtained by K. marxianus [3]. When cane molasses wastewater was supplemented with $6 \mathrm{~g} / \mathrm{L}$ of L-phenylalanine, $0.99 \mathrm{~g} / \mathrm{L}$ of 2-PhEtOH was produced using microbial mixed cultures [4]. A study with six isolated strains, all displayed the ability to produce $2-\mathrm{PhEtOH}$ in a range of $1.17-3.28 \mathrm{~g} / \mathrm{L}$ using a medium with $3 \%(w / v)$ whey supplemented with $3 \%(w / v)$ sugar beet (molasses, thick juice, or sludge II) and $5 \mathrm{~g}$ /L of L-phenylalanine [8]. Lastly, K. marxianus in grape must cultures, produces 2-PhEtOH at $0.47 \mathrm{~g} / \mathrm{L}$ when supplemented with $3.0 \mathrm{~g}$ of L-phenylalanine [9]. All the studies with residuals, use them in a complementary way, except the work by [9] where they use of the complete grape must and only supplemented with L-phenylalanine. This implies that the use of crude residues (undiluted) has not often been explored, much less has been optimized to produce 2-PhEtOH. The only antecedent of optimization with residuals is that reported by [9] where a central composite design and response surface methodology was used.

The yeast $K$. marxianus has the characteristic of growing and developing in lactose-rich media; therefore, it can be used to ferment residues from the cheese industry [2]. Sweet whey is considered a pollutant with a high content of organic matter, whose chemical oxygen demand (COD) values are between 6000-8000 mg/L [10], with a lactose content of 40 to $60 \mathrm{~g} / \mathrm{L}$ [11]. Previous research has highlighted the use of whey to produce higher alcohols such as 2-PhEtOH, that it is obtained from the Ehrlich pathway; however, although it is known that this route has a higher yield of metabolite production, it is affected by several factors $[2,12,13]$. The principals are the carbon, nitrogen and precursor source (L-phenylalanine). This relationship can affect production performance, as well as the accumulation of some metabolite, causing an inhibition of yeast growth [14]. 2-PhEtOH production optimization with crude sweet whey has two advantages, obtaining a product with high added value using an agro-industrial waste, as well as the significant reduction of the organic load of the waste that allows the subsequent waste treatment to be less expensive. In this way, a benefit is obtained from the waste treatment of a residue that is very difficult to eliminate and reduces the use of synthetic culture media. The use of 2-PhEtOH in the food industry is also favored as it comes from a GRAS microorganism (K. marxianus) [9].

The response surface methodology (RSM) is a set of mathematical and statistical tools, based on a multiple regression analysis using experimental data that yields equations that allow us to identify and statistically relate the multiple variables that affect the fermentation process, obtaining benefits such as an increase in production performance, reduction of time and cost of the process [14-17]. In this work, the best fermentation conditions were optimized and validated to produce 2-PhEtOH from sweet whey with $\mathrm{K}$. marxianus and the reduction of COD of the culture medium, by means of RSM, evaluating two parameters as a function of time: concentration of L-phenylalanine (precursor) and $\left(\mathrm{NH}_{4}\right)_{2} \mathrm{SO}_{4}$ (salt).

\section{Materials and Methods}

\subsection{Biological Material}

The Kluyveromyces marxianus strain was kept in petri dishes with Potato Dextrose Agar (PDA) medium, 39 g/L (Bioxon, Cuautitlán Izcalli, Estado de México, México); incubated for $24 \mathrm{~h}$ at $28^{\circ} \mathrm{C}$ and subsequently refrigerated at $4{ }^{\circ} \mathrm{C}$, until use [2]. For the inoculum of subsequent cultures with whey, the strain was grown in an LPY medium, lactose $(80 \mathrm{~g} / \mathrm{L})$ (Tecsiquim, Toluca de Laredo, México), casein peptone (40 g/L) (Bioxon, Cuautitlán Izcalli, Estado de México, México) and extract yeast (20 g/L) (MCD LAB, Tlalnepantla de Baz, Estado de México, México), at pH 4.8.

\subsection{Sweet Whey (Substrate)}

A $50 \mathrm{~L}$ batch of sweet whey was provided by the dairy producer PROUNILAC of the Autonomous University of the State of Hidalgo (Tulancingo de Bravo, Hidalgo, Mexico). Before refrigeration, the whey was pasteurized at $63{ }^{\circ} \mathrm{C}$ for $30 \mathrm{~min}$. The $\mathrm{pH}$ was adjusted to 4.8 , with a solution of $\mathrm{H}_{2} \mathrm{SO}_{4}$ at a concentration of $1 \mathrm{~N}$. The samples were kept in $10 \mathrm{~L}$ 
polypropylene containers, then they were transported with ice to the laboratory, where they were stored at $4{ }^{\circ} \mathrm{C}$, until its use.

\subsection{Experimental Design: Central Composite Design (CCD)}

To evaluate the fermentation conditions of 2-PhEtOH production (precursor and salt concentration), a rotatable composite central design (CCD) was used, the distance between the axial points to the center was $\alpha= \pm 1.41$. Four center points were established to provide a predicted stable reasonable variance $[14,15]$. The range and levels of the variables are presented in Table 1. The design was obtained with the help of Design Expert software version 11.1.

Table 1. Central Composite Design Matrix.

\begin{tabular}{ccc}
\hline Treatment. & $\mathbf{X}($ L-Phenylalanine $)$ & $\mathbf{Y}\left(\mathbf{( N H}_{\mathbf{4}} \mathbf{~}_{\mathbf{2}} \mathbf{S O}_{\mathbf{4}}\right)$ \\
\hline T1 & -1.41 & 0.0 \\
T2 & -1.0 & -1.0 \\
T3 & -1.0 & 1.0 \\
T4 & 0.0 & -1.41 \\
T5 & 0.0 & 0.0 \\
T6 & 0.0 & 0.0 \\
T7 & 0.0 & 0.0 \\
T8 & 0.0 & 0.0 \\
T9 & 0.0 & 1.41 \\
T10 & 1.0 & -1.0 \\
T11 & 1.0 & 1.0 \\
T12 & 1.41 & 0.0 \\
\hline
\end{tabular}

\subsection{Fermentation}

The strains were pre-grown in $250 \mathrm{~mL}$ Erlenmeyer flaks, containing a $100 \mathrm{~mL}$ working volume of yeast medium LPY and incubated at $28{ }^{\circ} \mathrm{C}$ for $24 \mathrm{~h}$ and $245 \mathrm{rpm}$. For the fermentation, the stains were inoculated at $1 \times 10^{6}$ cells per $\mathrm{ml}$ and incubated at $28{ }^{\circ} \mathrm{C}$ for $24 \mathrm{~h}$ and $245 \mathrm{rpm}$. The inoculum was added $(100 \mu \mathrm{L})$ to 24 -well plates (Fisher Scientific, Monterrey, Nuevo León, México), which working volume was $1.9 \mathrm{~mL}$, then was fixed in a support with orbital shaking ( $5 \mathrm{~mm}$ diameter shaking) [18]. Each well of the plate containing the inoculum was previously adjusted to the amount of $1 \times 10^{6}$ cells per $\mathrm{mL}$ and $100 \mu \mathrm{L}$ precursor and salt whose concentrations for each treatment (defined in Table 1), the remaining volume $1700 \mu \mathrm{L}$ was sweet whey pretreated (see 2.2) [19]. Every $24 \mathrm{~h}$, aliquots of $1 \mathrm{~mL}$ were taken from each well and placed in sterile plastic (Eppendorf, Coyoacán, Cuidad de México, México) tubes and analyzed by gas chromatography to detect the production of 2-PhEtOH. All fermentation were carried in triplicate.

\subsection{Optimization}

The optimization of the fermentation was carried out by the response surface methodology, using least squares with the Design Expert software 11.1. The objective function was a second-order model (Equation (1)) [14-17].

$$
Y=\beta_{0}+\sum_{i=1}^{k} \beta_{i} X_{i}+\sum_{i=1}^{k} \beta_{i i} X_{i}^{2}+\sum_{\substack{i, j \\ i<j}} \beta_{i, j} X_{i} X_{j}+\varepsilon
$$

where:

$\mathrm{Y}=$ Response variable.

$X_{i}$ and $X_{j}=$ Independent variables.

$\beta_{0}=$ Intersection coefficient.

$\beta_{i}=$ Linear coefficient.

$\beta_{\mathrm{ii}}=$ Quadratic coefficient. 
$\beta_{\mathrm{ij}}=$ Coefficient of cross products.

$\varepsilon=$ Random experimental error.

The validation of the model obtained for each fermentation time was carried out, performing mean comparisons with the same software mentioned above.

\subsection{Gas Chromatography (GC)}

The aliquots of $1 \mathrm{~mL}$ were previously centrifuged at $600 \mathrm{rpm}$ for $3 \mathrm{~min}$. The supernatant was removed and filtered with cellulose membrane $(0.2 \mu \mathrm{m})$ and placed in sterile plastic tubes (Eppendorf, Coyoacán, Cuidad de México, Mexico). The analysis was performed in a gas chromatograph (Thermo Fisher Scientific model, Trace 1310, Bremen, Germany) equipped with an FID detector and a DB WAX J\&W Scientifics column $(60 \mathrm{~m} \times 0.25 \mathrm{~mm} \times 0.25 \mu \mathrm{m})$. The injector and detector temperatures were set at $250{ }^{\circ} \mathrm{C}$ and $300{ }^{\circ} \mathrm{C}$, respectively.

The oven operated with a temperature ramp from 35 to $210^{\circ} \mathrm{C}$, with a heating rate of $50{ }^{\circ} \mathrm{C} / \mathrm{min}$ for $4 \mathrm{~min}$. The carrier gas was nitrogen at $1 \mathrm{~mL} / \mathrm{min}$. Compounds were identified and quantified through standard comparisons. Each injection was done in triplicate.

\subsection{Determination of the Chemical Oxygen Demand (COD)}

The COD was determined in all the samples by triplicate, following the standardized method 973.46E of the AOAC (1996). The reading was taken with a spectrophotometer (Thermo Scientific model BioMate 3S, Bremen, Germany) 44 at $600 \mathrm{~nm}$. The determination of the COD concentration was made with the calibration curve, expressed in $\mathrm{mg} \mathrm{O}_{2} / \mathrm{L}$. According to [20], the COD removal efficiency of each treatment used in the central compound design was calculated. The equation for determination is:

$$
\mathrm{R}=\left(\frac{\mathrm{Y}_{0}-\mathrm{Y}}{\mathrm{Y}_{0}}\right) \times 100
$$

where:

R: System removal efficiency (\%).

Y: Output pollutant load ( $\mathrm{mg} \mathrm{O}_{2} / \mathrm{L}$ COD or TSS/L).

$\mathrm{Y}_{0}$ : Inlet pollutant load ( $\mathrm{mg} \mathrm{O}_{2} / \mathrm{L}$ COD or TSS/L).

\subsection{Statistic Analysis}

For the validation of the obtained models, a means tests by LSD (least-squares deviation) was applied, with a confidence limit of $95 \%$, using the Design Expert software 11.1.

\section{Results}

\subsection{Production of 2-PhEtOH}

For 2-PhEtOH optimization, three experimental stages were carried out. First, two variables were selected according to preliminary studies, showing that the concentration of L-phenylalanine and salt influence aroma production [19]. Second, the best fermentation conditions were observed by obtaining the models, corroborating that the precursor concentration presents a statistically significant effect on the response. Finally, the conditions were verified to ratify the results obtained. Table 2 shows the analysis of variance of the respective models that were generated from experimental data. Likewise, the equations generated are presented in Table 3. 
Table 2. Analysis of variance of 2-PhEtOH production, at different fermentation times.

\begin{tabular}{|c|c|c|c|c|c|c|c|c|}
\hline \multirow{2}{*}{$\begin{array}{l}\text { Fermentation } \\
\text { Hours }\end{array}$} & \multirow{2}{*}{ Model } & \multicolumn{2}{|c|}{ Linear } & \multirow{2}{*}{$\begin{array}{c}\mathrm{P} / \mathrm{S} \\
\text { Interaction }\end{array}$} & \multicolumn{2}{|c|}{ Quadratic } & \multirow{2}{*}{ Lack of Fit } & \multirow{2}{*}{ Value of $R^{2}$} \\
\hline & & $\mathbf{P}$ & $S$ & & $\mathbf{P}^{2}$ & $S^{2}$ & & \\
\hline 24 & 28.85 & 141.20 & 1.38 & 0.19 & 0.61 & 1.14 & 0.47 & 0.80 \\
\hline 48 & 54.20 & 265.02 & 0.29 & 2.95 & 0.63 & 1.61 & 13.89 & 0.88 \\
\hline 72 & 30.05 & 66.52 & 1.19 & 2.86 & 79.53 & 3.96 & 4.46 & 0.82 \\
\hline 96 & 21.50 & 95.23 & 4.4 & 11.12 & 5.43 & 2.79 & 6.83 & 0.78 \\
\hline
\end{tabular}

Where: $\mathrm{P}$ is L-phenylalanine (precursor) and $\mathrm{S}$ the $\left(\mathrm{NH}_{4}\right)_{2} \mathrm{SO}_{4}$ (salt).

Table 3. Equations of the 2-PhEtOH production models.

\begin{tabular}{ccc}
\hline Fermentation Hours & Model & ${\text { Value of } \mathbf{R}^{\mathbf{2}}}$ \\
\hline 24 & $Y=-0.31+0.19 p+0.60 s+0.03 p * s-8.16^{-003} p^{2}-0.40 s^{2}$ & 0.80 \\
48 & $Y=0.70+0.19 p+1.17 s+0.15 p * s-9.05^{-003} p^{2}-0.52 s^{2}$ & 0.88 \\
72 & $Y=-0.38+0.72 p+0.71 s+0.18 p * s-0.12^{-003} p^{2}-0.91 s^{2}$ & 0.82 \\
96 & $Y=-0.34+0.30 p+0.13 s+0.18 p * s-0.01 p^{2}-0.34 s^{2}$ & 0.78 \\
\hline
\end{tabular}

Where: $\mathrm{P}$ is L-phenylalanine (precursor) and $\mathrm{S}$ the $\left(\mathrm{NH}_{4}\right)_{2} \mathrm{SO}_{4}$ (salt). * is a multiplication sign.

In the results of Table 2, the effect of the precursor and salt concentration on the response is observed, allowing to obtain the regressions (Table 3). The $\mathrm{R}^{2}$ values, of each of the fermentation times, present slightly low. However, the data indicate that the equations are adequate to analyze and establish the prediction of the changes in the concentration of 2-PhEtOH. The precursor concentration is the key factor since it has a value of $p<0.05$. The value of this factor can be positive or negative depending on the response. Although it depends on other factors that will be detailed later. The approximations of the best fermentation conditions are shown in Figure 1, which confirms the values and models observed in Tables 2 and 3. According to variations in $R^{2}$ of each model, it is recommended to perform a validation of the same.

A) 2-PhEtOH 24h.

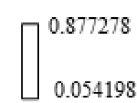

$\mathrm{X} 1=\mathrm{A}: \mathrm{A}$ (Precursor) $\mathrm{X} 2=\mathrm{B}: \mathrm{B}($ Salt $)$

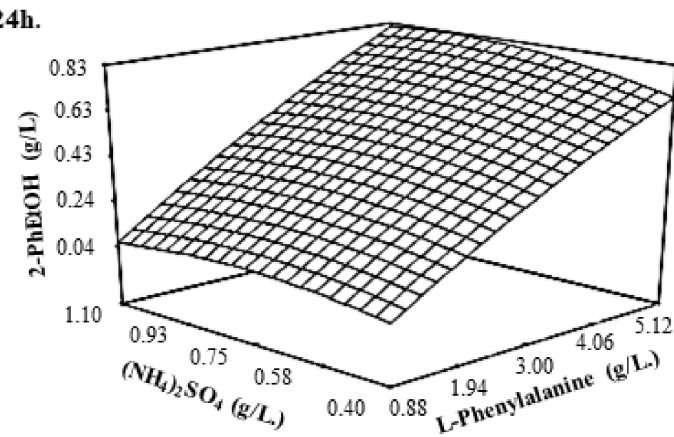

B) 2-PhEtOH 48h.

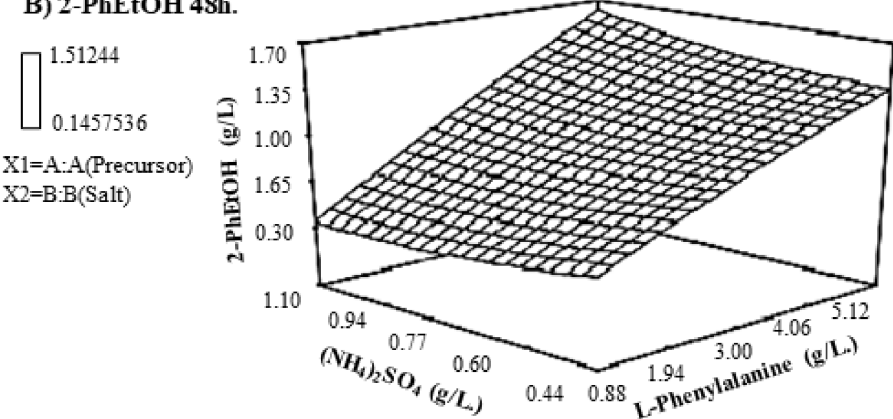

\section{C) 2-PhEtOH $72 \mathrm{~h}$}

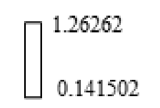

$\mathrm{X} 1=\mathrm{A}: \mathrm{A}$ (Precursor) $\mathrm{X} 2=\mathrm{B} \cdot \mathrm{B}$ (Salt)
D) 2-PhEtOH $96 \mathrm{~h}$.
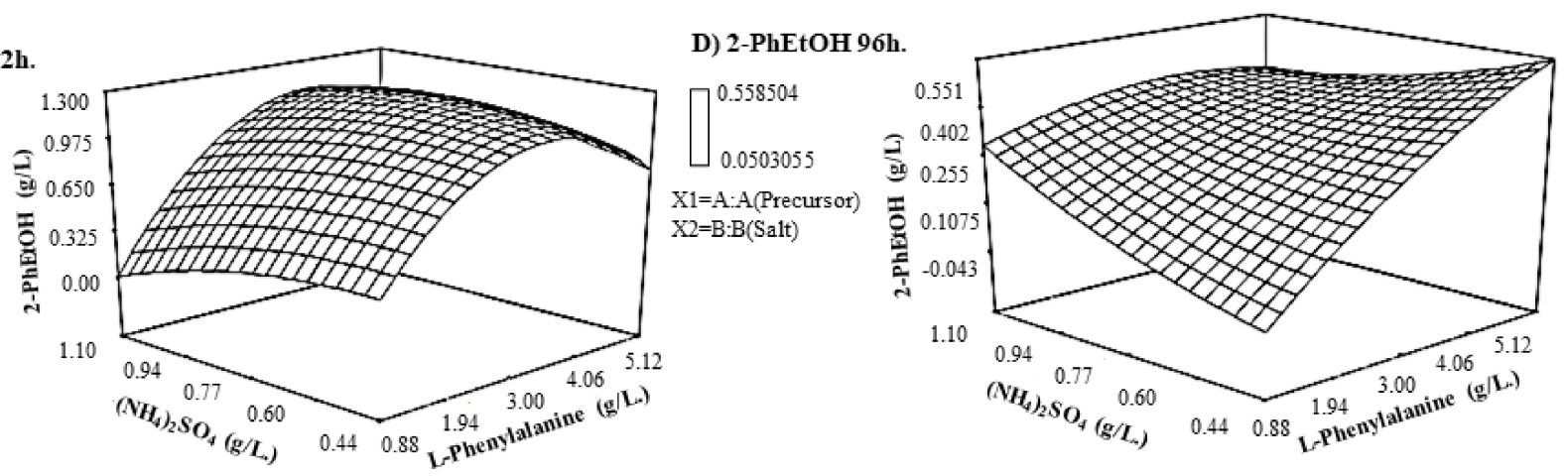

Figure 1. Response surfaces of the different fermentation times on 2-PhEtOH production, where (A) $24 \mathrm{~h},($ B) $48 \mathrm{~h},($ C) $72 \mathrm{~h}$ and (D) $96 \mathrm{~h}$. 
Table 4 shows the maximum concentration of the aroma, as well as the combination of precursor and salt for the generated values, highlighting the 48 and $72 \mathrm{~h}$. Since the maximum concentration of 2-PhEtOH was obtained, with 1.25 and $1.17 \mathrm{~g} / \mathrm{L}$, respectively.

Table 4. Production of 2-PhEtOH in different times.

\begin{tabular}{cccc}
\hline Fermentation Hours & $\begin{array}{c}\text { L-Phenylalanine } \\
(\mathbf{g} / \mathrm{L})\end{array}$ & $\mathbf{( N H}_{\mathbf{4}} \mathbf{~}_{\mathbf{2}} \mathbf{S O}_{\mathbf{4}} \mathbf{( g / L )}$ & 2-PhEtOH (g/L) \\
\hline 24 & 4.50 & 0.94 & 0.73 \\
48 & 4.50 & 0.52 & 1.25 \\
72 & 4.17 & 0.82 & 1.17 \\
96 & 4.50 & 1.00 & 0.39 \\
\hline
\end{tabular}

Figure 1A, B schematizes the fermentation at 24 and $48 \mathrm{~h}$ of culture, where a flat shape can be seen, attributable to a first-order model, while at 72 and $96 \mathrm{~h}$ it corresponds to a second-order model, which is appropriate to observe the maximum response within the study region.

\subsection{Decrease in $C O D$}

The COD concentration was determined at the beginning of the process, as well as in the different fermentation times, to determine the \% removal efficiency of organic matter according to the different treatments tested (Table 5).

Table 5. Initial COD concentration.

\begin{tabular}{|c|c|c|c|}
\hline Run & $\mathrm{COD}\left(\mathrm{mg} \mathrm{O} \mathrm{O}_{2} / \mathrm{L}\right)$ & Run & $\mathrm{COD}\left(\mathrm{mg} \mathrm{O}_{2} / \mathrm{L}\right)$ \\
\hline $\mathrm{T} 1$ & $50,955.63 \pm 4769.70$ & $\mathrm{~T} 7$ & $50,622.20 \pm 3883.73$ \\
\hline $\mathrm{T} 2$ & $52,111.41 \pm 2020.73$ & T8 & $50,288.97 \pm 3987.36$ \\
\hline T3 & $53,555.41 \pm 1802.78$ & T9 & $55,231.15 \pm 1443.38$ \\
\hline $\mathrm{T} 4$ & $51,455.23 \pm 4000.00$ & $\mathrm{~T} 10$ & $51,288.52 \pm 1258.31$ \\
\hline T5 & $50,312.17 \pm 1892.97$ & $\mathrm{~T} 11$ & $53,785.37 \pm 2516.61$ \\
\hline T6 & $50,122.30 \pm 3617.09$ & $\mathrm{~T} 12$ & $55,288.12 \pm 1607.28$ \\
\hline
\end{tabular}

The data reveal that the content of organic matter present in the sweet whey, surpasses the permissible limit for its discharge to water bodies [10]. This makes it a major environmental pollutant if not treated properly. That is why look alternatives for the use of sweet whey that generate added value, make its waste treatment attractive before disposing of it. The present study intends to link through optimization, the use of the precursor and salt in the production of 2-PhEtOH, with the maximum \% removal of COD (Tables 6 and 7).

Table 6. Analysis of variance of the decrease in COD, at different times of fermentation.

\begin{tabular}{|c|c|c|c|c|c|c|c|c|}
\hline \multirow{2}{*}{$\begin{array}{l}\text { Fermentation } \\
\text { Hours }\end{array}$} & \multirow[b]{2}{*}{ Model } & \multicolumn{2}{|c|}{ Linear } & \multirow{2}{*}{$\begin{array}{c}\mathrm{P} / \mathrm{S} \\
\text { Interaction }\end{array}$} & \multicolumn{2}{|c|}{ Quadratic } & \multirow[b]{2}{*}{ Lack of Fit } & \multirow[b]{2}{*}{$R^{2}$ Value } \\
\hline & & $\mathbf{P}$ & $S$ & & $\mathbf{P}^{2}$ & $S^{2}$ & & \\
\hline 24 & 26.14 & 77.40 & 17.35 & 6.25 & 40.58 & 0.05 & 1.22 & 0.83 \\
\hline 48 & 35.53 & 33.85 & 31.78 & 78.01 & 28.50 & 6.09 & 2.08 & 0.84 \\
\hline 72 & 26.21 & 31.90 & 15.24 & 9.54 & 5.04 & 84.85 & 10.15 & 0.81 \\
\hline 96 & 7.20 & 3.29 & 0.42 & 5.96 & 18.46 & 10.38 & 3.46 & 0.53 \\
\hline
\end{tabular}

Where: $\mathrm{P}$ is L-phenylalanine (precursor) and $\mathrm{S}$ the $\left(\mathrm{NH}_{4}\right)_{2} \mathrm{SO}_{4}$ (salt). 
Table 7. Equations of the COD models.

\begin{tabular}{ccc}
\hline Fermentation Time & Model & $\mathbf{R}^{2}$ Value \\
\hline 24 & $Y=36192.52-1663.25 p+6233.52 s-1143.96 p * s+319.24 p^{2}-452.44 s^{2}$ & 0.86 \\
48 & $Y=52467.59-9057.75 p-40206.26 s-6703.91 p * s+541.52 p^{2}-9965.45 s^{2}$ & 0.86 \\
72 & $Y=20248.27+395.57 p-7580.92 s-356.69 p * s-46.50 p^{2}+5448.47 s^{2}$ & 0.85 \\
96 & $Y=13152.85-32.51 p-15.961 s-65.63 p * s-88.85 p^{2}-8693 s^{2}$ & 0.620 \\
\hline
\end{tabular}

Where: L-phenylalanine (precursor) and $\left(\mathrm{NH}_{4}\right)_{2} \mathrm{SO}_{4}$ (salt). $*$ is a multiplication sign.

From both tables it is generally identified that almost all the terms, except for the quadratic of salt, are significant. This is corroborated with the $\mathrm{R}^{2}$ value. The use of models is recommended.

From Figure 2, the curvatures presented in the graphs are characteristic of a secondorder model, which is evident at $96 \mathrm{~h}$. The data of the \% removal of COD from sweet whey are presented in Table 8.

A) COD 24h.

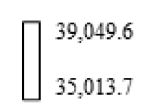

$\mathrm{X} 1=\mathrm{A}: \mathrm{A}$ (Precursor) $\mathrm{X} 2=\mathrm{B} \cdot \mathrm{B}$ (Salt)

\section{C) $\operatorname{COD} 72 \mathrm{~h}$.}

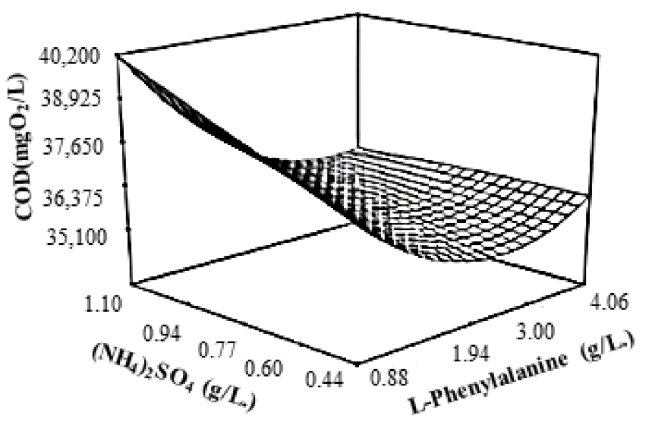

$\prod_{17,230.9}^{18,472.8}$

$\mathrm{X} 1=\mathrm{A}: \mathrm{A}($ Precursor) $\mathrm{X} 2=\mathrm{B} \cdot \mathrm{B}$ (Salt)
B) COD 48h.

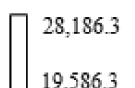

$\mathrm{X} 1=\mathrm{A}: \mathrm{A}$ (Precursor) $\mathrm{X} 2=\mathrm{B}: \mathrm{B}$ (Salt)

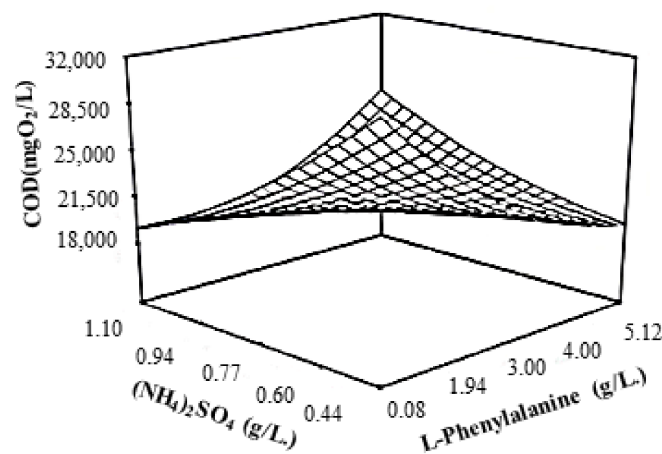

D) COD 96h.

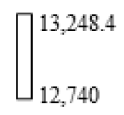

$\mathrm{X} 1=\mathrm{A} \cdot \mathrm{A}$ (Precursor) $\mathrm{X} 2=\mathrm{B}: \mathrm{B}$ (Salt)

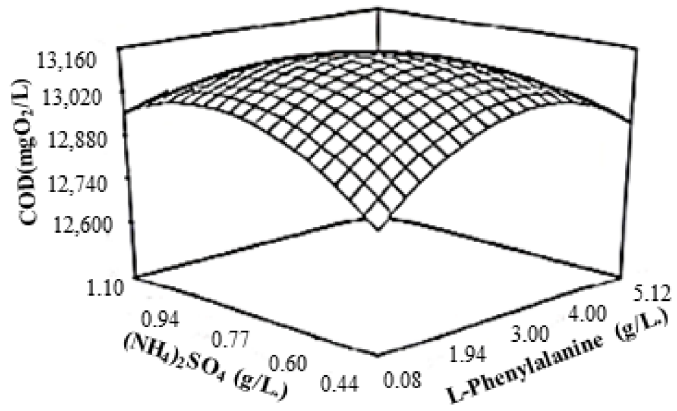

Figure 2. COD response surface, at the different fermentation times, where (A) $24 \mathrm{~h},(\mathbf{B}) 48 \mathrm{~h},(\mathbf{C}) 72 \mathrm{~h}$ and (D) $96 \mathrm{~h}$.

Table 8. Removal of COD in different fermentation times.

\begin{tabular}{|c|c|c|c|}
\hline Fermentation Time & $\begin{array}{c}\text { Initial COD } \\
\left(\mathrm{mg} \mathrm{O}_{2} / \mathrm{L}\right)\end{array}$ & $\begin{array}{c}\text { Final COD } \\
\left(\mathrm{mg} \mathrm{O}_{2} / \mathrm{L}\right)\end{array}$ & \% Removal. \\
\hline 24 & $53,785.37 \pm 2516.61$ & $35,792.65 \pm 2987.98$ & 33 \\
\hline 48 & $51,288.52 \pm 1258.31$ & $20,147.97 \pm 1413.56$ & 60 \\
\hline 72 & $55,288.12 \pm 1607.28$ & $17,316.14 \pm 1095.36$ & 68 \\
\hline 96 & $53,785.37 \pm 2516.61$ & $12,863.38 \pm 1078.22$ & 76 \\
\hline
\end{tabular}

Table 8 identifies that, at $96 \mathrm{~h}$, the maximum \% removal of 76\% was obtained, demonstrating the efficacy of the applied treatments. 


\subsection{Validation of the Models}

Of the twelve applied treatments, those with the highest 2-PhEtOH production were selected, to validate the proposed models at 48, 60 and $72 \mathrm{~h}$ (Figure 3).

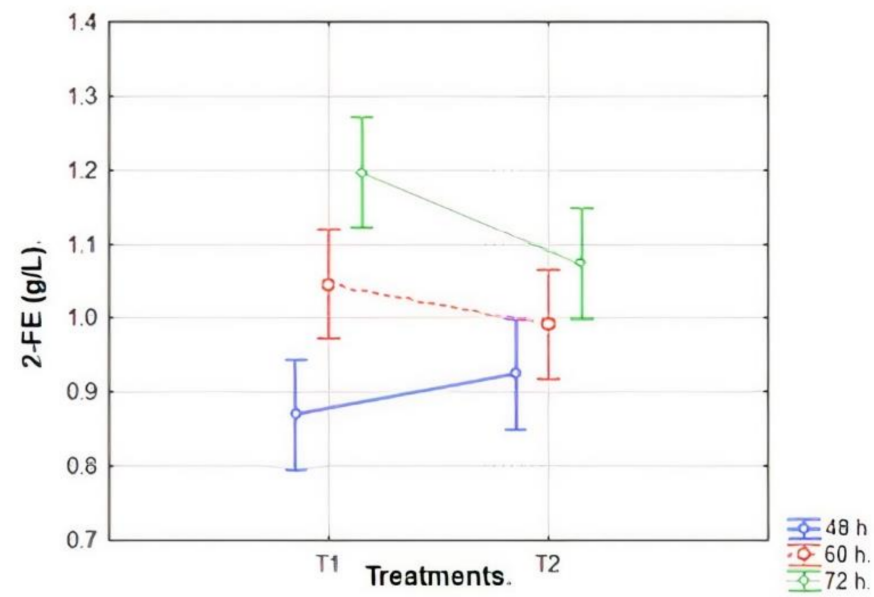

Figure 3. Mean comparisons (LSD) of the 2-PhEtOH production conditions.

The mean comparison graph (Figure 3), shows that treatment 1 (T1) produces the lower amount of 2-PhEtOH, under the conditions predicted by the model, while at $60 \mathrm{~h}$ the yeast produces approximately $1 \mathrm{~g} / \mathrm{L}$ and at $72 \mathrm{~h}$ it produces $1.2 \mathrm{~g} / \mathrm{L}$. Whereas treatment T2 produces a greater metabolite concentration at $48 \mathrm{~h}$. Although a large increase in production is not observed with respect to 60 and $72 \mathrm{~h}$, with a production of $1.08 \mathrm{~g} / \mathrm{L}$. The aroma concentration is like the aforementioned results, for which the use of the obtained models is recommended to predict future responses.

\section{Discussion}

The microbial fermentation process is complex, since small variations in the composition of the media and the study conditions influence the yields of the metabolites, as well as causing changes in the metabolism of the strain [21-23]. Investigations carried out by various authors support the fundamental role of the concentration of the carbon and nitrogen sources [3,19]. One study report that have different nitrogen source during fermentation significantly reduces the production of higher alcohols in cultures of Hanseniaspora Vinae, showing that cultivation conditions and yeast species are important factors. Therefore, although it is difficult to determine the optimal fermentation conditions, the RSM is a powerful tool to optimize the fermentation medium of $K$. marxianus during aroma production, according to the experimental results and the analysis of variance of the obtained models. The statistically significant factor is the content of the amino-acid L-phenylalanine present in the fermentation broth $(p<0.05)$. This can be attributed to the fact that the Ehrlich pathway is favored, since L-phenylalanine is the precursor of this. The difference with the Shikimate pathway is that it has several regulations, related to the feedback of metabolic branches that implies more steps to achieve bioconversion $[7,24,25]$.

The physiologic response of the strain is related with the culture medium composition. It plays an important role in avoiding the synthesis of unwanted by-products and impacts the fermentation efficiency of any product of interest [26]. Therefore, from Figure 1A can be seen, at $24 \mathrm{~h}$, a flat shape attributable to a first-order model, indicating that it is not yet on optimal region [15]. This behavior serves as a starting point to guide towards the best conditions of the experiment, where preferably it should be presented a curvature (second-order model). At $48 \mathrm{~h}$ (Figure 1B), a same behavior it observed, first-order model was obtained again with a considerable lack of adjustment, which may be attributable to the fact that it was always trying to fit a second-order model. One way to counteract this inconvenience is to eliminate terms that affect the response. However, it is necessary to 
establish a hierarchical order of the candidates to be eliminated, since it may or may not benefit the error [15]. However, this begins to observe a curvature, which indicates an approach to a second-order model.

The production of 2-PhEtOH at 72 and $96 \mathrm{~h}$ (Figure 1C,D), shows graphs corresponding to a second-order model, which allows to observe a maximum response within the study region. Table 4 shows the maximum aroma concentration, as well as the combination of precursor and salt necessary to achieve it. The 48 and $72 \mathrm{~h}$ stand out, because it obtained the maximum concentration of 2-PhEtOH, the values were 1.25 and $1.17 \mathrm{~g} / \mathrm{L}$, respectively. It has been reported that working with $1 \mathrm{~g} / \mathrm{L}$ of L-phenylalanine and $0.45 \mathrm{~g} / \mathrm{L}$ of $\left(\mathrm{NH}_{4}\right)_{2} \mathrm{SO}_{4}$, aroma production values of $0.78 \mathrm{~g} / \mathrm{L}$ at $96 \mathrm{~h}$ will obtained [24]. Under these conditions, it can see that the applied treatments improve the fermentation time, the main objective of optimizing a process. Some authors suggest considering the ethanol production; 2-PhEtOH and ethanol show a synergistic effect, inhibiting yeast proliferation, recommending avoiding the accumulation of both during the fermentation process $[7,19,27]$. The last can be disregarded due to Crabtree effect in K. Marxianus. Recently, [28] concluded that under micro-aeration conditions and a high content of carbon source (inulin) the production of ethyl alcohol could be favored. For this reason, it is intuited that the system of this study follows this way. Therefore, it is suggested to carry out new studies considering aeration as variables.

As pointed out in the introduction, few studies explore the use of industrial waste to produce aromatic compounds, especially using them crude, that is, undiluted. The review carried out by [6] presents an analysis of the investigations that have used agro-industrial residues. Like the grape must, where the production of $2-\mathrm{PhEtOH}$ was $0.39 \mathrm{~g} / \mathrm{L}$ with $3 \mathrm{~g} / \mathrm{L}$ of precursor in $84 \mathrm{~h}$ of culture. Like the present study, they optimized production, taking $\mathrm{pH}$, temperature and precursor concentration as variables [8]. In another report [18], with sugar beet molasses, reaching $0.89 \mathrm{~g} / \mathrm{L}$ with $7 \mathrm{~g} / \mathrm{L}$ of L-phenylalanine in $41 \mathrm{~h}$. The concentration of 2-PhEtOH in the present study is higher than those reported.

The data obtained reveal that the content of organic matter (Table 5) present in the sweet whey, exceeds the permissible limit for its discharge into water bodies [10]. As a result, the environmental problems range from phenomena such as eutrophication impacting the life and development of aquatic species, as well as the proliferation of unpleasant odors. Obtaining polynomials and response surface graphs (Table 6 and Figure 2) allows not only to relate the effect of the precursor and salt on the production of 2-PhEtOH, but the role they play with the \% COD removal, where the significant factors of are the salt content and precursor. This were corroborated with the behavior of the graphs (Figure 2), which correspond to a second-order model given the curvature they present, being more evident at $96 \mathrm{~h}$. In Table 8, at $96 \mathrm{~h}$, the maximum removal percentage was obtained with $76 \%$, demonstrating the efficacy of the applied treatments by reducing three-quarters of the initial COD load. Another study where the reduction of the organic load of the whey was explored for K. marxianus, reporting a reduction up to $64.3 \%$ with an initial content of $51,500 \mathrm{mg} \mathrm{O}_{2} / \mathrm{L}$, within the first 10-12 h under aerobic conditions [29].

This can be a consequence of the Crabtree effect in yeasts, which major example is defined as a preferential fermentation process due to high levels of carbohydrates, even under aerobic conditions [30]. It is classified as positive and negative. Saccharomyces cerevisiae it is a Crabtree-positive yeast, characterized by not producing biomass, due to its sensitivity to high glucose concentrations, preferring to carry out alcoholic fermentation instead of breathing [31]. Contrary, with K. marxianus, a Crabtree-negative yeast, can grow under aerobic conditions in the presence of high levels of carbon source. For this reason, although ethanol production was not determined in the present work, it cannot be considered as a variable that influenced the production of 2-PhEtOH. Since K. marxianus, being Crabtree-negative, does not produce ethanol under aerobic conditions even under high carbohydrate loads, which allows consuming a greater amount of them in shorter periods of time. The low tendency in K. marxianus to produce alcohol might be a consequence of its capacity of keeping a glycolytic flux constant, due in part to the diversion of carbon 
flux towards the biosynthesis of carbohydrates and towards the pentose phosphate pathway [32]. Therefore, K. marxianus is considered effective for the rapid conversion of carbon sources [31]. This was also observed by [29], who reported higher percentages of decrease in organic matter, which for practical purposes meets its objective. While the objective of the present work was not only to reduce the COD, but also to obtain the maximum production of 2-PhEtOH. The results of the experimental validation of the precursor and salt concentration estimates were positive and close to previously observed. Therefore, the use of models is recommended to predict future responses. Optimizing the use of waste in the raw state (undiluted), to produce value-added metabolites, has operational and economic advantages. At an operational level, it allows lower operating volumes and, as observed in this study, it contributes to the remediation of sweet whey, with which a significant economic benefit could be obtained [6].

\section{Conclusions}

Through the response surface methodology, using a central compound design, the production of 2-Phenylethanol was optimized, from the fermentation of sweet whey with Kluyveromyces marxianus. The optimal values found were $4.50 \mathrm{~g} / \mathrm{L}$ of L-phenylalanine and $0.76 \mathrm{~g} / \mathrm{L}$ of $\left(\mathrm{NH}_{4}\right)_{2} \mathrm{SO}_{4}$, reaching a metabolite formation of $1.2 \mathrm{~g} / \mathrm{L}$ in $48 \mathrm{~h}$.

The analysis of variance of the twelve treatments, allowed us to visualize the significance of the precursor and the salt to increase the production of 2-PhEtOH and decrease the COD, finding that L-phenylalanine has a significant effect. When validating the results, the use of models is recommended. Finally, it is important to emphasize the complexity of the organic matter used for this work, since it is precisely this that makes the optimization of the process a challenge. For future research it is necessary to design an aroma recovery mechanism, preferably as it is produced, to enhance the production of 2-PhEtOH and give it better use to the added precursor.

Author Contributions: Conceptualization, M.A.-V., A.C.-R. and C.A.G.-A.; methodology, M.A.-V., L.C.-B., C.A.G.-A. and M.d.R.R.-V.; software, C.A.G.-A. validation, M.A.-V., C.A.G.-A. and A.T.-J.; formal analysis, M.A.-V. and C.A.G.-A.; investigation, M.A.-V. and A.C.-R.; resources, A.C.-R., C.A.G.-A., M.d.R.R.-V., J.C.-R. and A.T.-J.; data curation, M.A.-V. and C.A.G.-A.; writing-original draft preparation, M.A.-V. and A.C.-R.; writing-review and editing, M.A.-V., A.C.-R.; visualization, M.A.-V., A.C.-R., L.C.-B. and M.d.R.R.-V.; supervision, A.C.-R., C.A.G.-A.; project administration, A.C.-R. and C.A.G.-A.; funding acquisition, A.C.-R. and C.A.G.-A. and J.C.-R. All authors have read and agreed to the published version of the manuscript.

Funding: This research received no external funding.

Institutional Review Board Statement: Not applicable.

Informed Consent Statement: Not applicable.

Data Availability Statement: No extra data are available.

Acknowledgments: The first author thanks the support to Consejo Nacional de Ciencia y Tecnología (CONACYT) for the scholarship awarded to obtain the master's degree in biotechnology on the postgraduate program of Universidad Politécnica de Pachuca, included in the National Quality Postgraduate Program.

Conflicts of Interest: The authors declare no conflict of interest.

\section{References}

1. Etschmann, M.; Sell, D.; Schrader, J. Screening of yeasts for the production of the aroma compound 2-phenylethanol in a molasses-based medium. Biotechnol. Lett. 2003, 25, 531-536. [CrossRef]

2. Etschmann, M.; Sell, D.; Schrader, J. Medium optimization for the production of the aroma compound 2-phenylethanol using a genetic algorithm. J. Mol. Catal. B Enzym. 2004, 29, 187-193. [CrossRef]

3. Sarkar, N.; Ghosh, S.K.; Bannerjee, S.; Aikat, K. Bioethanol production from agricultural wastes: An overview. Renew. Energ. 2012, 37, 19-27. [CrossRef] 
4. $\mathrm{Mu}, \mathrm{L} . ; \mathrm{Hu}, \mathrm{X}$; Liu, X.; Zhao, Y.; Xu, Y. Production of 2-phenylethanol by microbial mixed cultures allows resource recovery of cane molasses wastewater. Fresen Environ. Bull. 2014, 23, 1356-1365.

5. Longo, M.A.; Sanromán, M.A. Production of food aroma compounds: Microbial and enzymatic methodologies. Food Technol. Biotechnol. 2006, 44, 335-353.

6. Mitri, S.; Koubaa, M.; Maroun, R.G.; Rossignol, T.; Nicaud, J.M.; Louka, N. Bioproduction of 2-Phenylethanol through Yeast Fermentation on Synthetic Media and on Agro-Industrial Waste and By-Products: A Review. Foods 2022, 11, 109. [CrossRef]

7. Rodríguez-Romero, J.J.; Aceves-Lara, C.A.; Ferreira-Silva, C.; Gschaedler, A.; Amaya-Delgado, L.; Arrizon, J. 2-Phenylethanol and 2-phenylethylacetate production by nonconventional yeasts using tequila vinasses as a substrate. Biotechnol. Rep. 2020, 25, e00420. [CrossRef] [PubMed]

8. Chreptowicz, K.; Sternicka, M.K.; Kowalska, P.D.; Mierzejewska, J. Screening of yeasts for the production of 2-phenylethanol (rose aroma) in organic waste-based media. Lett. Appl. Microbiol. 2018, 66, 153-160. [CrossRef]

9. Garavaglia, J.; Flores, S.H.; Pizzolato, T.M.; do Carmo Peralba, M.; Ayub, M.A.Z. Bioconversion of L-phenylalanine into 2-phenylethanol by Kluyveromyces marxianus in grape must cultures. World J. Microbiol. Biotechnol. 2007, 23, 1273-1279. [CrossRef]

10. Spalatelu, C. Biotechnological valorization of whey. Innov. Rom. Food Biotechnol. 2012, 10, 1-8.

11. Prazeres, A.R.; Carvalho, F.; Rivas, J. Cheese whey management: A review. J. Environ. Manag. 2012, 110, 48-68. [CrossRef] [PubMed]

12. Qian, X.; Yan, W.; Zhang, W.; Dong, W.; Ma, J.; Ochsenreither, K.; Jiang, M.; Xin, F. Current status and perspectives of 2phenylethanol production through biological processes. Crit. Rev. Biotechnol. 2019, 39, 235-248. [CrossRef]

13. Hua, D.; Xu, P. Recent advances in biotechnological production of 2-phenylethanol. Biotechnol. Adv. 2011, 29, 654-660. [CrossRef]

14. Montgomery, D. Design and Analysis of Experiments, 8th ed.; Wiley: Hoboken, NJ, USA, 2012; pp. 478-544.

15. Corona-González, R.; Ramos-Ibarra, J.; Gutiérrez-González, P.; Pelayo-Ortiz, C.; Guatemala-Morales, G.; Arriola-Guevara, E. The use of response surface methodology to evaluate the fermentation conditions in the production of tepache. Rev. Mex. Ing. Quim. 2020, 12, 19-28.

16. Hernández-Díaz, W.N.; Hernández-Campos, F.J.; Vargas-Galarze, Z.; Rodríguez-Jiménez, G.C.; García-Alvarado, M.A. Coffee Grain Rotary Drying Optimization. Rev. Mex. Ing. Quim. 2013, 12, 315-325.

17. Téllez-Mora, P.; Peraza-Luna, F.A.; Feria-Velasco, A.; Andrade-González, I. Optimization of fermentation process for tequila production using response surface methodology (RSM). Rev. Mex. Ing. Quím. 2020, 11, 163-176.

18. Ramírez-Vargas, R.; Vital-Jacome, M.; Camacho-Pérez, E.; Hubbard, L.; Thalasso, F. Characterization of oxygen transfer in a 24-well microbioreactor system and potential respirometric applications. J. Biotechnol. 2014, 186, 58-68. [CrossRef]

19. Conde-Báez, L.; Castro-Rosas, J.; Villagómez-Ibarra, J.R.; Páez-Lerma, J.B.; Gómez-Aldapa, C. Evaluation of waste of the cheese industry for the production of aroma of roses (Phenylethyl alcohol). Waste Biomass Valori. 2017, 8, 1343-1350. [CrossRef]

20. Bong-yul, T.; Bong-sik, T.; Young-ju, K.; Yong-jin, P.; Young-hun, Y.; Gil-ho, M. Optimization of color and COD removal from livestock wastewater by electrocoagulation process: Application of Box-Behnken design (BBD). J. Ind. Eng. Chem. 2015, 28, 307-315.

21. Yun, T.Y.; Feng, R.J.; Zhou, D.B.; Pan, Y.Y.; Chen, Y.F.; Wang, F.; Yin, L.Y.; Zhang, Y.D.; Xie, J.H. Optimization of fermentation conditions through response surface methodology for enhanced antibacterial metabolite production by Streptomyces sp. 1-14 from cassava rhizosphere. PLoS ONE 2018, 13, e0206497. [CrossRef]

22. Kaur, H.; Arora, D.S.; Sharma, V. Isolation, purification, and characterization of antimicrobial compound 6-[1, 2-dimethyl-6-(2methyl-allyloxy)-hexyl]-3-(2-methoxy-phenyl)-chromen-4-one from Penicillium sp. HT-28. Appl. Biochem. Biotechnol. 2014, 8 , 1963-1976. [CrossRef] [PubMed]

23. Scherlach, K.; Hertweck, C. Triggering cryptic natural product biosynthesis in microorganisms. Org. Biomol. Chem. 2009, 7, 1753-1760. [CrossRef] [PubMed]

24. Liu, J.; Jiang, J.; Bai, Y.; Fan, T.-P.; Zhao, Y.; Zheng, X. Mimicking a new 2-phenylethanol production pathway from Proteus mirabilis JN458 in Escherichia coli. J. Agric. Food Chem. 2018, 13, 3498-3504. [CrossRef]

25. Yin, S.; Zhou, H.; Xiao, X.; Lang, T.; Liang, J.; Wang, C. Improving 2-Phenylethanol Production via Ehrlich Pathway using genetic engineered Saccharomyces cerevisiae strains. Curr. Microbiol. 2015, 70, 762-767. [CrossRef]

26. Dubencovs, K.; Liepins, J.; Suleiko, A.; Suleiko, A.; Vangravs, R.; Kassaliete, J.; Scerbaka, R.; Grigs, O. Optimization of Synthetic Media Composition for Kluyveromyces marxianus Fed-Batch Cultivation. Fermentation 2021, 7, 62. [CrossRef]

27. Wang, H.; Dong, Q.; Guan, A.; Meng, C.; Shi, X.; Guo, Y. Synergistic inhibition effect of 2-phenylethanol and ethanol on bioproduction of natural 2-phenylethanol by Saccharomyces cerevisiae and process enhancement. J. Biosci. Bioeng. 2011, 1, 26-31. [CrossRef] [PubMed]

28. Ha-Tran, D.M.; Nguyen, T.T.M.; Huang, C.-C. Kluyveromyces marxianus: Current State of Omics Studies, Strain Improvement Strategy and Potential Industrial Implementation. Fermentation 2020, 6, 124. [CrossRef]

29. Gutierrez, E.; Bastidas, M. Optimal reduction of the organic load of sweet whey through the growth of Kluyveromyces marxianus. Afinidad LXXIII 2015, 575, 185-190.

30. De Deken, R.H. The Crabtree effect: A regulatory system in yeast. J. Gen. Microbiol. 1966, 44, 149-156. [CrossRef] [PubMed] 
31. Karim, A.; Gerliani, N.; Aïder, M. Kluyveromyces marxianus: An emerging yeast cell factory for applications in food and biotechnology. Int. J. Food Microbiol. 2020, 333, 108818. [CrossRef] [PubMed]

32. Bellaver, L.H.; de Carvalho, N.M.B.; Abrahão-Neto, J.; Gombert, A.K. Ethanol formation and enzyme activities around glucose-6phosphate in Kluyveromyces marxianus CBS 6556 exposed to glucose or lactose excess. FEMS Yeast Res. 2004, 4, 691-698. [CrossRef] [PubMed] 